\section{Discussion of "Soil Water Retention Characteristics of Vertisols and Pedotransfer Functions Based on Nearest Neighbor and Neural Networks Approaches to Estimate AWC" by N. G. Patil, D. K. Pal, C. Mandal, and D. K. Mandal}

\author{
February 2012, Vol. 138, No. 2, pp. 177-184.
}

DOI: $10.1061 /(A S C E) I R .1943-4774.0000375$

\begin{abstract}
G. Provenzano ${ }^{1}$; G. Giordano ${ }^{2}$; and G. Rallo ${ }^{3}$
${ }^{1}$ Associate Professor, Dipartimento Scienze Agrarie e Forestali, Università degli Studi, Viale delle Scienze 12, 90128 Palermo, Italy. E-mail: giuseppe.provenzano@unipa.it

${ }^{2}$ Full Professor, Dipartimento Scienze Agrarie e Forestali, Università degli Studi, Viale delle Scienze 12, 90128 Palermo, Italy. E-mail: giuseppe .giordano@unipa.it

${ }^{3}$ Junior Investigator, Dipartimento Scienze Agrarie e Forestali, Università degli Studi, Viale delle Scienze 13, 90128 Palermo, Italy (corresponding author). E-mail: rallo.giovanni@gmail.com
\end{abstract}

In the original paper, the authors deal with the quite interesting topic related to the evaluation of available water capacity (AWC) of vertisols, also exploring the possibility of using pedotransfer functions (PTFs). The high water-holding capacity of vertisols due to the high clay content makes these soils suitable for dry-land crop production. Evaluation of the maximum amount of water stored in the soil and available for growing crops has practical relevance to estimate crop water requirements and to manage irrigation scheduling (Bittelli and Flury 2009). The problem is significant not only in India, where approximately 70 million ha are vertisols, but also in other tropical, subtropical, and warm temperate zones of the world, where vertisols and associated soils cover approximately 257 million ha of the Earth's surface (Dudal and Bramao 1965).

In the original paper, AWC was evaluated according to the volumetric water contents, $\theta$, at matric potentials of -33 and $-1,500 \mathrm{kPa}$ obtained on the basis of soil water retention curves' parameters. Such parameters were estimated either on measured data or on PTFs built using two different techniques, i.e., the artificial neural networks (ANNs) - based regression (Shaap et al. 1998; Minasny et al. 1999) and the $k$-nearest neighbor $(k-\mathrm{NN})$ approach (Nemes et al. 2006).

Initially the authors, considering the unpublished database developed by Pal et al. (2003), identified the four best parametric functions able to describe the soil water retention curves (SWRCs) of vertisols. The considered database contains a detailed physical characterization of 26 different Indian soil profiles collected in different regions, including soil particle size distribution determined with the pipette method, and seven points of SWRC obtained on sieved soil samples with pressure plate apparatus in the range of soil matric potential variable between -33 and $-1,500 \mathrm{kPa}$.

Agreeing with the authors' conclusions, the discussers believe that the parameters of the different functions expressing the SWRC and the consequent evaluation of the models' performance are affected by the lack of experimental data on soil water contents close to saturation and also by the neglected variation of soil bulk density (BD) with water content. Furthermore, the technique used to determine soil water content at matric potentials of -33 and
$-100 \mathrm{kPa}$ could also have affected the final results. For those values of matric potential, in fact, soil water retention characteristics must be determined on undisturbed soil samples for which the original pore geometry is maintained, while the use of pressure plate apparatus on disturbed soil samples is appropriate for values of soil matric potential lower than $-100 \mathrm{kPa}$ (Dirksen 1999; Cresswell et al. 2008).

Moreover, according to the information provided in the original paper, soil bulk density should have been determined on thin undisturbed soil blocks $8-\mathrm{cm}$ long, 6-cm wide, and 5-cm thick; even if it is not indicated in the original paper, the discussers suppose that those values were considered to evaluate volumetric soil water contents from measured gravimetric water contents.

Actually, the physical properties of vertisols are strongly influenced by the soil water content. In fact, changes in soil volume occur as a consequence of change in soil water content and, after long dry periods, deep and wide cracks can be visible in the soil. These volumetric changes determine variation in soil pores' geometry during drying or wetting processes, affecting the soil bulk density-water content relationship (Allbrook 1993), and consequently the water stored in the soil profile. According to Mitchell (1992), the volume changes can be expressed through the so-called "soil shrinkage characteristic curve" (SSCC), representing the relationship between specific volume of soil $(\nu)$ and gravimetric water content $(U)$. Since Haines (1923), numerous researches have been focusing on experimental methodologies to measure the SSCC, on evaluation of its parameters using simplified procedures (Crescimanno and Provenzano 1999), and on errors on estimation of volumetric soil water contents when SSCC is neglected (Crescimanno and Provenzano 1995).

Ignoring increasing soil bulk density at decreasing soil moisture can cause an overestimation of AWC, with differences rising at increasing percentages of swelling clays in the soil.

In order to assess the errors in AWC obtained when neglecting the soil bulk density variations, the discussers will present some experimental data obtained on 25 swelling soils, most of which were vertisols, extracted from a bigger unpublished database collected in the Delia River catchment (southwest of Sicily, Italy), where vineyards and olive orchards are the main crops. The soils are characterized by clay contents ranging from 18 to $65 \%$ and soil $\mathrm{BD}$ ranging between a minimum of $1.07 \mathrm{~g} / \mathrm{cm}^{3}$ at saturation and a maximum of $1.89 \mathrm{~g} / \mathrm{cm}^{3}$ obtained after oven-drying the samples.

For each site, two undisturbed cylindrical cores, $8-\mathrm{cm}$ diameter and 5-cm high, were collected in order to measure SWRCs and SSCCs. Soil particle distributions were initially determined by sieving and sedimentation with the ASTM 152H hydrometer. The hanging water column apparatus was used to determine on undisturbed samples gravimetric water contents $(U)$ corresponding to pressure heads $(h)$ equal to $-0.1,-0.5,-1.0,-4.0,-7.0$, and $-12.0 \mathrm{kPa}$. Pressure plate apparatus with sieved soil samples $(5-\mathrm{cm}$ diameter and 1-cm height) allowed evaluation of $U$ for $h$ values equal to $-33,-100,-300$, and $-1,500 \mathrm{kPa}$. On the same undisturbed samples, SSCCs were determined during a drying period from saturation to oven dry. Immediately after weighting the samples, vertical shrinkage was measured on nine marked surface positions with a dial vernier caliper bolted to a fixed bar, allowing a precision of $0.1 \mathrm{~mm}$. When the samples were approaching airdryness condition, the samplers were removed and the circumference of the cores measured with a flexible tape. The soil samples were finally oven dried and the vertical shrinkage remeasured. 
For each soil water content, the value of soil-specific volume was determined according to a geometry factor, accounting for the relative amount of vertical shrinkage caused by the changes in total volume (Bronswijk 1990).

Table 1 shows the summary of physical properties of the investigated soils, including the values of soil BD $\left(\mathrm{g} \mathrm{cm}^{-3}\right)$, and gravimetric water content, $U\left(\mathrm{~g} \mathrm{~g}^{-1}\right)$, obtained at -33 and $-1,500 \mathrm{kPa}$. For the considered soil properties the corresponding standard error (SE), coefficient of variation (CV) minimums and maximums are also indicated.

Crescimanno and Provenzano (1999), to avoid the timeconsuming experimental measurements necessary to determine the SSCC, proposed a simple linear regression model to calculate the specific volume in the range of water contents between saturation and air dry. The slope of the line can be predicted on the basis of the soil clay content, $C(\%)$ according to the following relationship obtained on soil cores:

Table 1. Summary of Physical Properties of the Investigated Soils

\begin{tabular}{lccccc}
\hline Soil property & Mean & SE & CV & Minimum & Maximum \\
\hline Sand (\%) & 24.2 & 11.7 & 0.48 & 2.0 & 42.8 \\
Silt (\%) & 32.7 & 6.5 & 0.20 & 22.7 & 44.9 \\
Clay (\%) & 43.0 & 12.5 & 0.29 & 18.0 & 65.3 \\
Organic matter (\%) & 1.60 & 0.4 & 0.28 & 0.48 & 2.31 \\
BD at $-0.1 \mathrm{kPa}\left(\mathrm{g} \mathrm{cm}^{-3}\right)$ & 1.20 & 0.08 & 0.06 & 1.09 & 1.43 \\
BD at $-33 \mathrm{kPa}\left(\mathrm{g} \mathrm{cm}^{-3}\right)$ & 1.32 & 0.07 & 0.05 & 1.21 & 1.52 \\
$\mathrm{BD}$ at $-1,500 \mathrm{kPa}\left(\mathrm{g} \mathrm{cm}^{-3}\right)$ & 1.45 & 0.09 & 0.06 & 1.26 & 1.62 \\
$U$ at $-33 \mathrm{kPa}\left(\mathrm{g} \mathrm{g}^{-1}\right)$ & 0.31 & 0.06 & 0.21 & 0.18 & 0.42 \\
$U$ at $-1,500 \mathrm{kPa}\left(\mathrm{g} \mathrm{g}^{-1}\right)$ & 0.13 & 0.00 & 0.02 & 0.18 & 0.42 \\
\hline
\end{tabular}
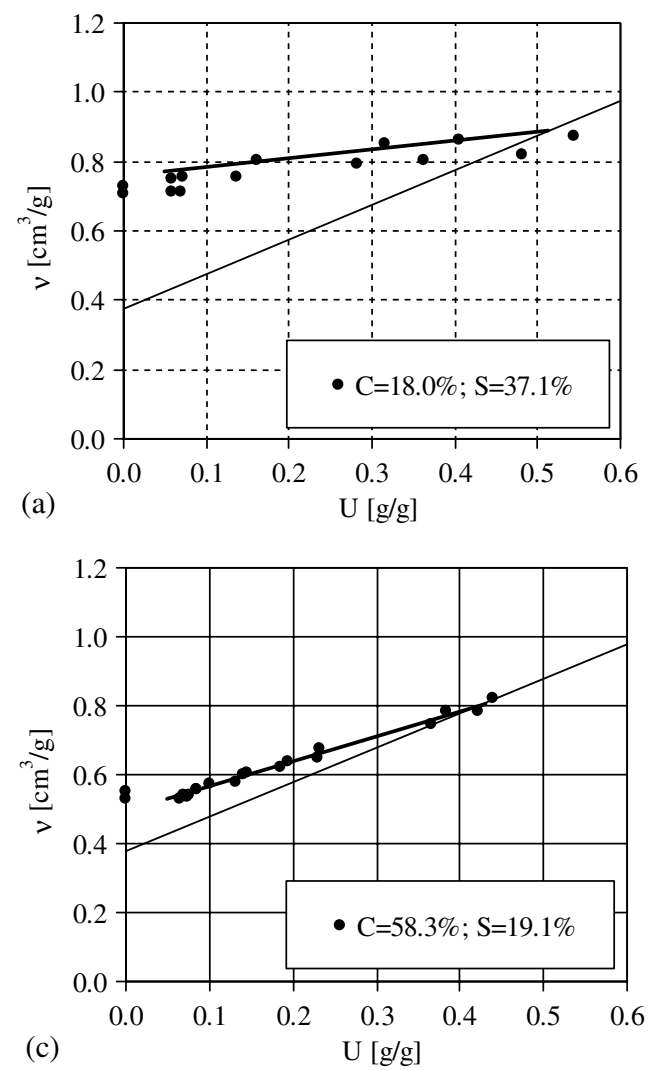

$$
n=0.0494+0.116 C
$$

characterized by a correlation coefficient equal to 0.90 and a standard error of estimate of 0.093 . Moreover, the knowledge of the specific volume, $\nu_{\text {sat }}$, at saturation $\left(U=U_{s}\right)$, is equal to

$$
\nu_{\mathrm{sat}}=U_{s}+\frac{1}{D}
$$

where $D=$ soil particles' density, which allows the prediction of the entire $\nu(U)$ relationship as

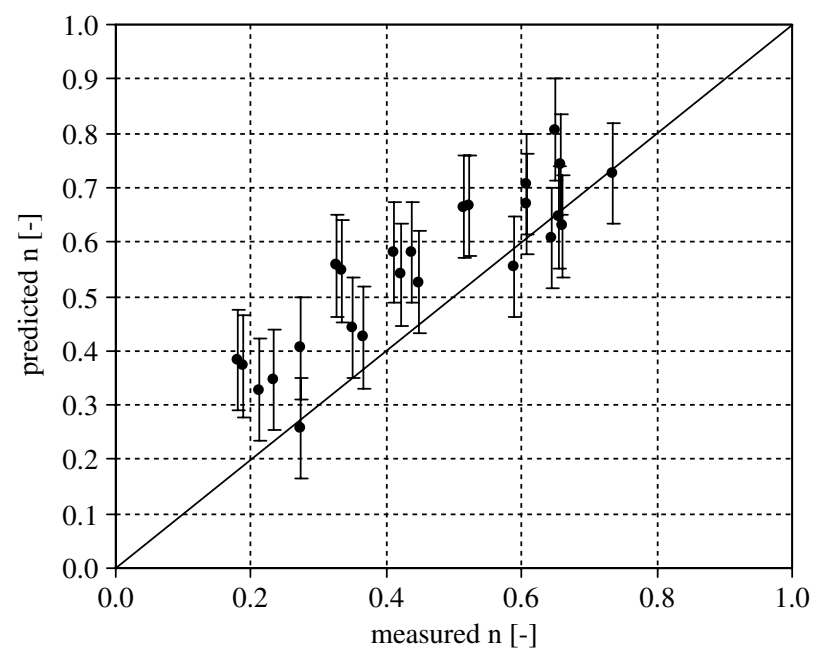

Fig. 2. Measured and predicted slope, $n$, of the soil shrinkage characteristic curve; standard error of estimate is equal to 0.093
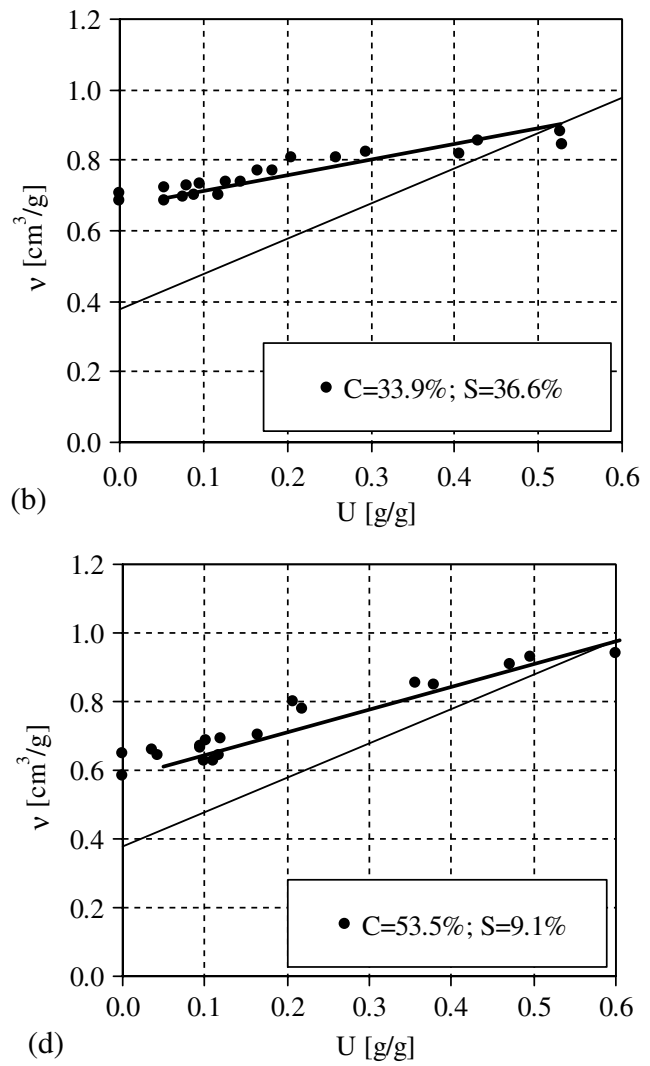

Fig. 1. SSCCs experimentally obtained and linear predictive model 


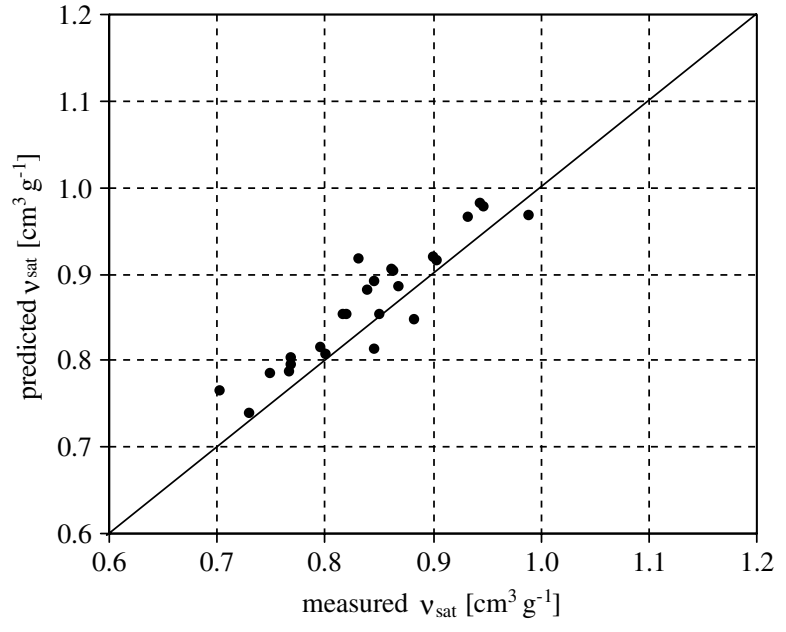

Fig. 3. Comparison between measured specific volume at saturation, $\nu_{\text {sat }}$, with the corresponding values predicted by Eq. (2)

$$
\nu=U_{s}+\frac{1}{D}-n\left(U_{s}-U\right)
$$

Fig. 1 shows the SSCCs experimentally obtained for four of the considered samples characterized by different clay content and the linear model represented by Eq. (3), being the slope $n$ predicted with Eq. (1), on the basis of the clay content. In order to confirm the predictive regression model on an independent data set for all
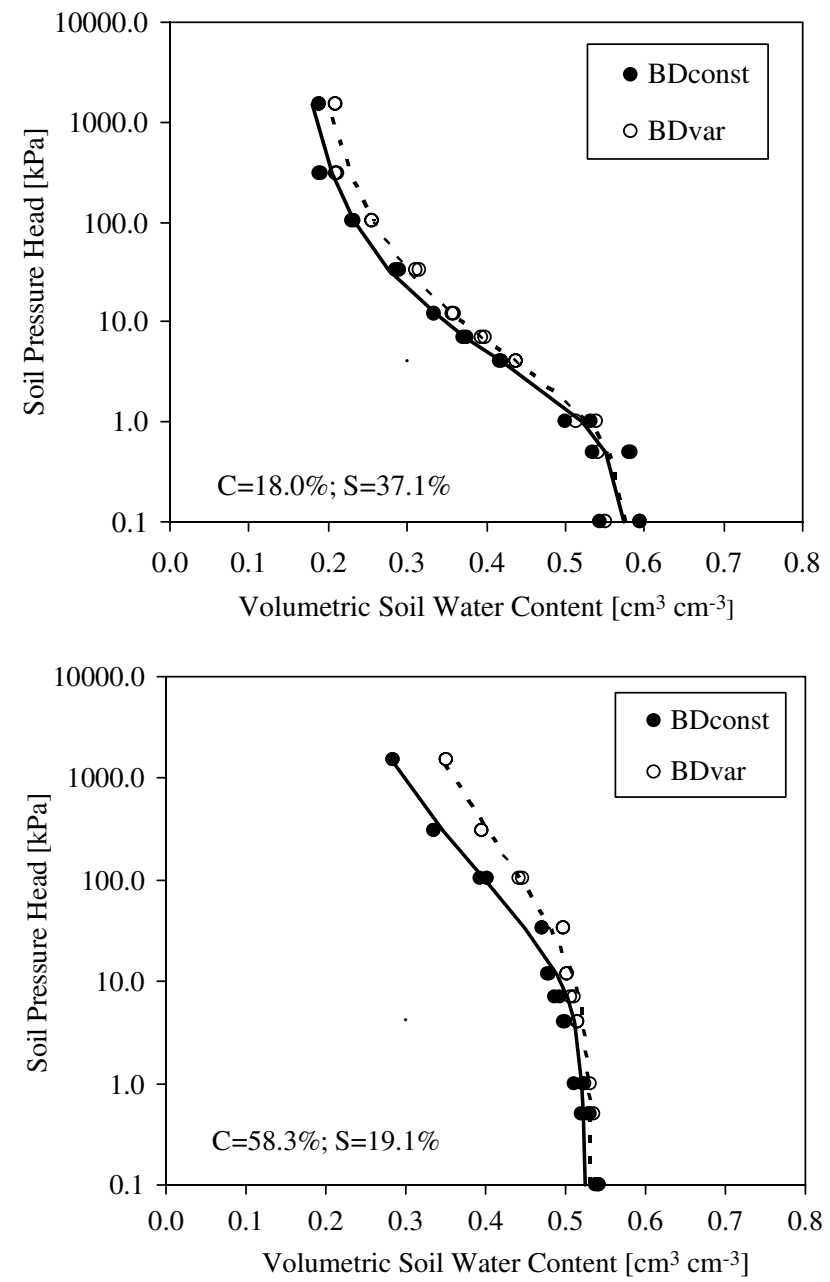

the soils considered in this discussion, Fig. 2 shows the measured and predicted slope of the shrinkage curve, whereas Fig. 3 illustrates the comparison between measured specific volume at saturation and the corresponding values predicted by Eq. (2).

Despite the slight overestimation observed in the estimates of $n$ and $\nu_{\text {sat }}$, in absence of measured SSCCs, Eqs. (1)-(3) can be considered a quite simple tool to estimate the specific volume as a function of the soil water content once the soil clay content is known. This approach allows consideration of the shrinkage behavior in laboratory-determined SWRCs.

For the examined soil samples, Fig. 4 shows the comparison between the SWRCs obtained, taking into account the variations of the soil bulk density $\left(\mathrm{BD}_{\mathrm{var}}\right)$, with those determined under the hypotheses of a constant value of bulk density ( $\left(\mathrm{BD}_{\text {const }}\right)$, measured on saturated soil. The van Genuchten model was used to fit the available data pairs. As can be observed in Fig. 4, for each sample and for a fixed soil matric potential, the volumetric water content calculated considering the soil shrinkage $\left(\mathrm{BD}_{\mathrm{var}}\right)$ is higher than the corresponding value obtained supposing the soil bulk density is constant $\left(\mathrm{BD}_{\text {const }}\right)$. These differences in volumetric water contents are equal to zero for $\theta=\theta_{\text {sat }}$ and increase at decreasing $\theta$ due to the increasing bulk density. Moreover, the higher the clay content for a fixed matric potential, the more evident is the difference between volumetric water contents calculated under variable and constant bulk density. Considering all the investigated soils, Fig. 5 shows the comparison between AWC values obtained as the difference between $\theta_{-33 \mathrm{kPa}}$ and $\theta_{-1,500 \mathrm{kPa}}$ calculated with
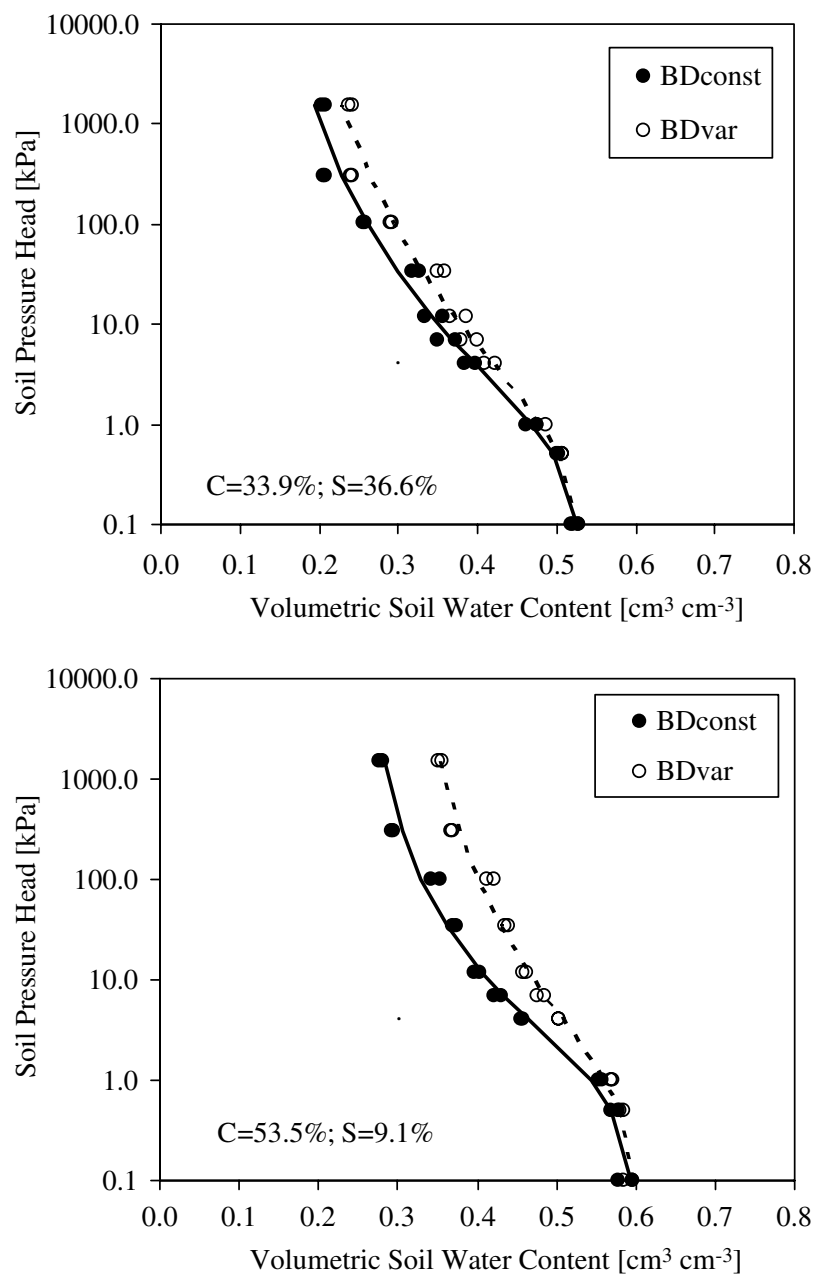

Fig. 4. SWRCs obtained accounting for and neglecting the variations of the soil bulk volume; van Genuchten model was used to fit the data 


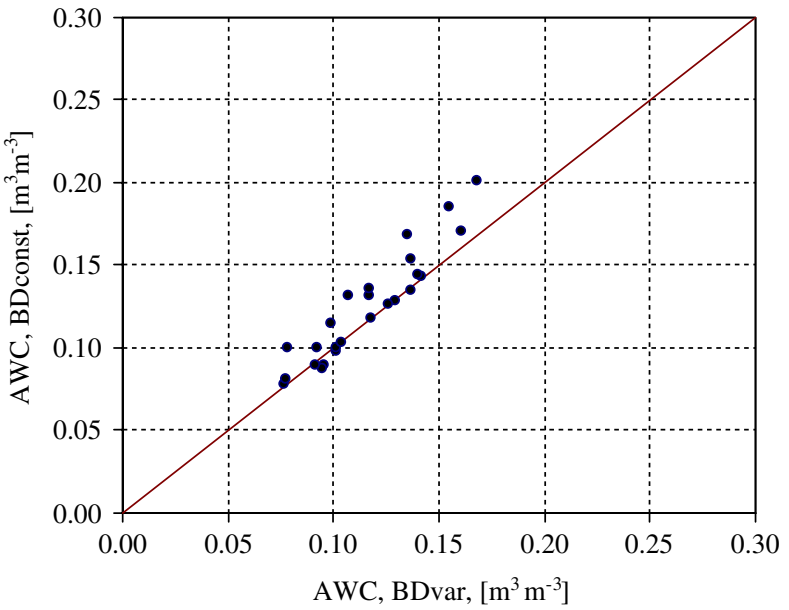

Fig. 5. Comparison between AWC values obtained considering constant and variable soil bulk density

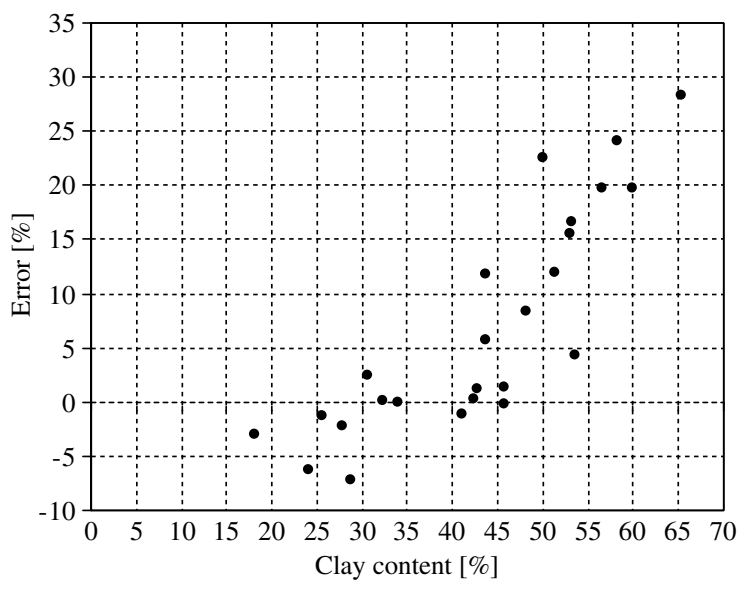

Fig. 6. Errors in AWC as a function of the clay content of the sample

$\mathrm{BD}_{\mathrm{var}}$ and $\mathrm{BD}_{\text {const }}$. As can be observed, neglecting the variation of the soil bulk density can produce an overestimation of AWC.

Fig. 6 shows the errors in AWC as a function of the clay content of the sample. Errors were calculated as the difference between AWC obtained considering constant and variable bulk density and expressed as percentage of the latter value. As can be observed in the figure, for clay content higher than approximately $40 \%$, the errors on AWC tend to increase with the clay percentage, reaching a maximum value of approximately $30 \%$ when the clay content results are slightly higher than $65 \%$.

For the examined reasons, despite the limits associated with the fitting of SWRC in absence of measurements close to saturation, the suggested procedure should be considered by the authors in order to improve the quality of the database used to evaluate AWC.

\section{References}

Allbrook, R. F. (1993). "Shrinkage of some New Zealand soils and its implications for soil physics." Aust. J. Soil Res., 31(2), 111-118.

Bittelli, M., and Flury, M. (2009). "Errors in water retention curves determined with pressure plates." Soil Sci. Soc. Am. J., 73(5), 1453-1460.

Bronswijk, J. J. B. (1990). "Shrinkage geometry of a heavy clay soil at various stress." Soil Sci. Soc. Am. J., 54(5), 1500-1502.

Crescimanno, G., and Provenzano, G. (1995). "Fenomeni di rigonfiamento e contrazione dei terreni argillosi. Indagine sperimentale dell'ambiente Siciliano." Rivista di Ingegneria Agraria, 3(5), 166-174 (in Italian).
Crescimanno, G., and Provenzano, G. (1999). "Soil shrinkage characteristic curve in clay soils: Measurement and prediction." Soil Sci. Soc. Am. J., 63(1), 25-32.

Cresswell, H. P., Green, T. W., and McKenzie, N. J. (2008). "The adequacy of pressure plate apparatus for determining soil water retention." Soil Sci. Soc. Am. J., 72(1), 41-49.

Dirksen, C. (1999). "Soil physic measurements." Geoecology paperback, Catena Verlag, Reiskirchen, Germany.

Dudal, R., and Bramao, D. L. (1965). "Dark clay soils of tropical and subtropical regions." FAO Agricultural Development Paper No. 8., Food and Agriculture Organization (FAO), Rome.

Haines, W. B. (1923). "The volume-changes associated with variations of water content in soil." J. Agric. Sci., 13(3), 296-310.

Minasny, B., McBratney, A. B., and Bristow, K. L. (1999). "Comparison of different approaches to the development of pedotransfer functions for water retention curves." Geoderma, 93(3-4), 225-253.

Mitchell, A. R. (1992). "Shrinkage terminology: Escape from "normalcy.", Soil Sci. Soc. Am. J., 56(3), 993-994.

Nemes, A., Rawls, W. J., and Pachepsky, Ya. A. (2006). "Use of the non parametric nearest neighbor approach to estimate soil hydraulic properties." Soil Sci. Soc. Am. J., 70(2), 327-336.

Pal, D. K., Bhattacharyya, T., Ray, S. K., and Bhuse, S. R. (2003). "Developing a model on the formation and resilience of naturally degraded black soils of the peninsular India as a decision support system for better land use planning." Project report, Nagpur, India.

Schaap, M. G., Leij, F. J., and van Genuchten, M. T. (1998). "Neural network analysis for hierarchical prediction of soil hydraulic properties." Soil Sci. Soc. Am. J., 62(4), 847-855.

\section{Closure to "Soil Water Retention Characteristics of Vertisols and Pedotransfer Functions Based on Nearest Neighbor and Neural Networks Approaches to Estimate AWC" by N. G. Patil, D. K. Pal, C. Mandal, and D. K. Mandal}

February 2012, Vol. 138, No. 2, pp. 177-184.

DOI: 10.1061/(ASCE)IR.1943-4774.0000375

N. G. Patil ${ }^{1}$

${ }^{1}$ Senior Scientist, National Bureau of Soil Survey and Land Use Planning, P.O. Shankarnagar Amravati Rd., Nagpur, Maharashtra 440010, India. E-mail: nitpat03@yahoo.co.uk

Soil water retention characteristics (SWRCs) must be determined on undisturbed soil samples, for which the original pore geometry is maintained. However, pressure plate analysis to obtain SWRCs as reported in the original paper was done long before the authors' work on SWRC functions and pedotransfer functions (PTFs). The authors realized this lacunae much later. A partial correction was done when the lead author analyzed SWRCs of waterlogged vertisols (Patil et al. 2010).

Because soils of the study area were of a shrink-swell type (smectitic clay), measurements on water retention at various suction points were corrected for overburden caused by soil swelling. Coefficient of linear extensibility (COLE) was calculated as suggested by Schafer and Singer (1976) as follows:

$$
\mathrm{COLE}=(\mathrm{Lm} \times \mathrm{Ld})=\mathrm{Ld}
$$

where $\mathrm{Lm}=$ moist soil-cylinder length $(\mathrm{mm})$; and $\mathrm{Ld}=$ dry soil-cylinder length $(\mathrm{mm})$. Soil porosity was assumed at 0.5 for calculating overburden caused by swelling. At each suction point, water-retaining pores were calculated using a standard capillary 
equation. Positive potential created by the overburden of water retained in the swelled portion was calculated as a product of the mass of water in pores $(\mathrm{g})$ and linear swelling $(\mathrm{mm} / \mathrm{mm})$. These values were converted to pascals and added to the applied equilibrium pressure. Soil water characteristics curves were thus obtained using the corrected nine-point data applying varied suction. Soil bulk density was determined from undisturbed soil samples (core samples).

Because the study soils exhibited shrink-swell characteristics, it would be pertinent to estimate a soil shrinkage characteristics curve (SSCC) and calibrate PTFs with and without consideration to shrinkage. Such analysis will provide an insight to the hydraulic behavior of these soils in general and functions describing SWRC. Crescimanno and Provenzano (1999) have proposed a simple linear-regression model to calculate the specific volume in the range of water contents between saturation and air dry. The slope of the line can be predicted on the basis of the soil clay content, $C(\%)$, according to the following relationship obtained on soil cores:

$$
n=0.0494+0.116 \mathrm{C}
$$

characterized by a correlation coefficient equal to 0.90 and a standard error of estimate of 0.093. Moreover, the knowledge of the specific volume, $\nu_{s}$, at saturation $\left(U=U_{s}\right)$, equal to

$$
\nu_{s}=U_{s}+1 / D
$$

where $D=$ soil particles' density, allows the prediction of the entire $\nu(U)$ relationship as

$$
\nu=U_{s}+1 / D-n\left(U_{s}-U\right)
$$

SSCC analysis was not performed or reported in the original paper, but because the soils are high in clay content the use of the previous equation will definitely alter the original available water capacity (AWC) database, leading to changes in the PTFs and estimates obtained. It would be interesting to see qualitative changes in the database.

\section{References}

Crescimanno, G., and Provenzano, G. (1999). "Soil shrinkage characteristic curve in clay soils: Measurement and prediction." Soil Sci. Soc. Am. J., 63(1), 25-32.

Patil, N. G., Rajput, G. S., Nema, R. K., and Singh, R. B. (2010). "Predicting hydraulic properties of seasonally impounded soils." J. Agr. Sci., 148(2), 159-170.

Schafer, W. M., and Singer, M. J. (1976). "A new method of measuring shrink-swell potential using soil pastes." Soil Sci. Soc. Am. J., 40(5), 805-806.

\section{Discussion of "New Theoretical Solution of the Stage-Discharge Relationship for Sharp-Crested and Broad Weirs" by V. Ferro}

March 2012, Vol. 138, No. 3, pp. 257-265.

DOI: 10.1061/(ASCE)IR.1943-4774.0000397

Amir H. Azimi, A.M.ASCE ${ }^{1}$ and N. Rajaratnam, F.ASCE ${ }^{2}$

${ }^{1}$ Postdoctoral Fellow, Dept. of Civil and Environmental Engineering, Univ. of Alberta, Edmonton AB, Canada T6G 2W2 (corresponding author). E-mail: azimi@ualberta.ca

${ }^{2}$ Professor Emeritus, Dept. of Civil and Environmental Engineering, Univ. of Alberta, Edmonton AB, Canada T6G 2W2. E-mail:nrajaratnam@ ualberta.ca
The author is complimented for attempting to develop a general formulation for all types of weirs including rectangular sharpcrested and broad-crested weirs, oblique weirs, labyrinth weirs, triangular sharp-crested (Thomson) weirs, and sharp-crested weirs with parabolic profiles, using dimensional considerations and the incomplete self-similarity theory. In his formulation, as presented in Eqs. (3)-(5) of the paper under discussion, for rectangular weirs, $k_{s}$ could be seen to be equal to the critical depth. Then Eq. (5) becomes simply $h=$ by $_{c}$, where $b$ depends on $h / p$ for sharp-crested weirs. For rectangular weirs of finite crest length, from the recent work of Azimi and Rajaratnam (2009), it appears that $b$ will depend upon $h / L$ in addition to $h / p$ where $\mathrm{L}$ is the length of the weir in the direction of flow.

For a sharp-crested weir, according to the Rehbock correlation (Kandaswamy and Rouse 1957)

$$
C_{D}=0.605+0.08 \frac{h}{P}
$$

This formulation does not work for relatively smaller weir heights. Swamee (1988) developed the following correlation for the whole range of weir heights as

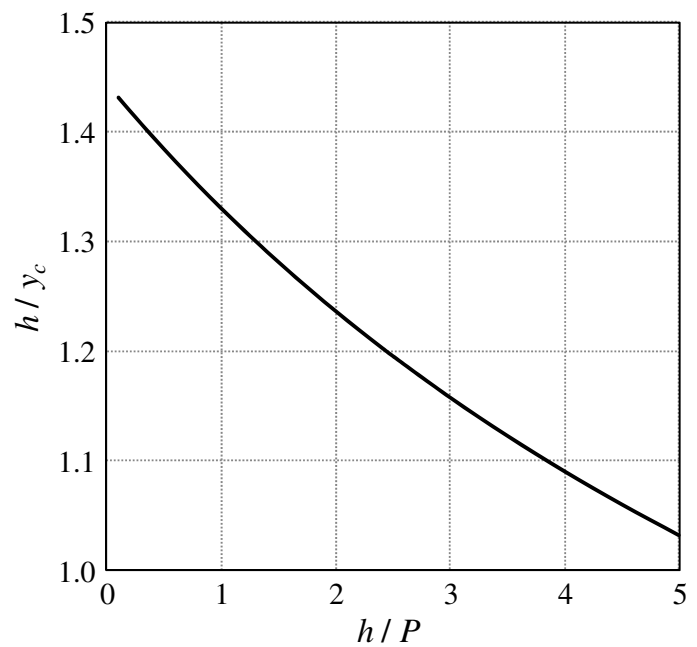

Fig. 1. Comparison of the head-critical depth ratio for sharp-crested weirs

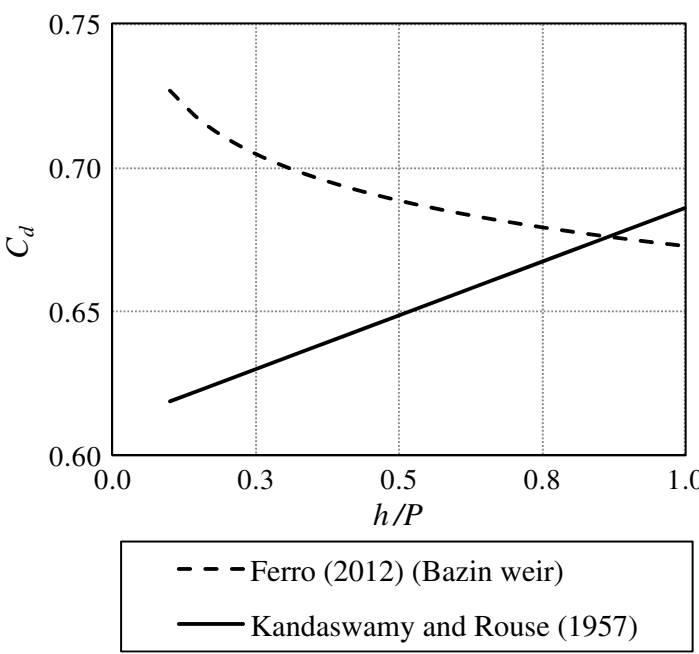

Fig. 2. Comparison between the proposed formulations for the sharpcrested weirs 